\title{
This Is Water Revisited: Creativity Lost
}

\author{
Eugene V. Beresin $^{1} \cdot$ Richard Balon $^{2} \cdot$ John H. Coverdale $^{3} \cdot$ Alan K. Louie $^{4}$
}

Received: 22 April 2015 /Accepted: 24 April 2015 / Published online: 8 May 2015

(C) Academic Psychiatry 2015

Laura Roberts, in her essay "Water Pie: Creativity and Leadership in Academic Psychiatry" [1], worries about the state of modern psychiatry, medicine, and real threats to creativity.

Should we be worried? Definitely!

But before considering the forces surrounding us that thwart creative thinking, let us look at the foundation for creative process. Creativity is the essence of new discovery-in science, the arts, humanities, medicine, economics, politics, and virtually every field. As Andreasen and Ramchandran [2] point out, "The capacity to be creative is one of the most important characteristics that human beings possess" (p. 49). The inception of virtually every revolutionary scientific theory derived from creative thinking and astute observations, most of the time combined. If not for thinking outside the box, outside the constraints of accepted principles, our greatest discoveries would be lost. Consider germ theory, relativity theory, the theory of evolution, quantum theory, theories on environmental causes of cancer, attachment theory, psychoanalysis, modern psychopharmacology, and, most recently, advances in genetics and epigenetics - these and many other epic conceptual frameworks would never have surfaced. As the preponderance of scientists tell us, first the concept and theory and then the proof.

Eugene V. Beresin

eberesin@partners.org

1 Harvard Medical School, Boston, MA, USA

2 Wayne State University, Detroit, MI, USA

3 Baylor College of Medicine, Houston, TX, USA

4 Stanford University School of Medicine, Stanford, CA, USA
Many visionaries, from Nicolaus Copernicus, Galileo Galilei, Sigmund Freud, Leonardo da Vinci, and Benjamin Franklin to Albert Einstein, risked and lived through ridicule. They questioned commonly accepted theories and proposed alternatives. As Thomas Kuhn reminds us in The Structure of Scientific Revolutions [3], all scientific theories are self-contained. Any data that defy consistency within the confines and framework of theory are thrown out as recalcitrant [3]. Further, Willard van Orman Quine [4], a modern pragmatist philosopher, argues that there is indeterminacy of translation from one theory to another-evidence alone does not dictate scientific theory.

Scientific theories are by nature constructs and have internal consistency and elegance. They are "true" but only relative to a context. Take Newtonian physics. It just does not work when particles are traveling close to the speed of light. Then, the theory of relativity takes over as an explanatory framework. Einstein's creative imagination led him to move beyond an accepted and validated theoretical model and create an entirely different one. He did not passively take the current model for granted but actively considered alternatives. He asked different questions. It takes the freedom to question accepted principles to go beyond accepted views and standards. Although all theories require "proof," they begin and end as a creative process. And we know that this was the way the theory of relativity evolved.

\section{Is Creativity in Psychiatry and Medicine Lost?}

Even within medicine, outlying theory is often rejected summarily if it does not fit into individual or mainstream thought. For example, we now know that meditation works. It not only works clinically but also has been demonstrated to change structural parts of the brain. But when Herbert Benson began studying its impact on control of the autonomic nervous 
system, he was heckled. Creativity as truly innovative thinking has not always been viewed positively enough in the modern era of science and medicine. We actually perceive that several processes have stifled creativity.

First, one of the basic requirements for creativity in academia, academic freedom, is evaporating, disappearing. Political correctness and unspoken rules of what could be said, and mainly what could not (even expressing oneself in electronic correspondence), limit the free exchange of ideas that foster creativity. For example, it took many years and considerable struggle to even begin to incorporate "alternative" therapies, such as Reike, acupuncture, or meditation, into our modern treatment arsenal. Innovative psychotherapies have faced similar histories. By the same token, appreciation of the power of epigenetics, such as parent-child attachment on the phenotypic expression of genes, was long considered off limits or, at best, met with frowns and unapologetic questioning. Fang and Casadevall [5] wrote, "Important scientific findings arise from unfettered exploration, the passion of individual scientists to understand a problem, and research environments that foster interaction" (p. 1231). Does the current atmosphere of rules of conversation and limits on exchange do enough to foster this interaction and creativity?

Second, medicine, psychiatry, and academia are increasingly run like a business. Business emphasizes just one aspect of creativity - creativity to make more money. And the business of medicine and psychiatry in its mission for fiscal productivity has far too often stifled academic, clinical, and theoretical creativity by virtue of increasingly rigid regulations for certification and practice and a demanding focus on relative value units. Donald Klein [6], reminiscing on the early "disorienting, delirious, exhilarating, and enchanting" times (p. 1063) of his research career (1950-1970), notes, "Chance favors the prepared mind, said Pasteur, but there must be proper environments that foster chance observations, allowing prepared minds to pursue promising leads" (p. 1064). He continues, "The bottom line approach of managed care and the insurance industry effectively destroyed this form of [hospital-based] research support" and "the current clinical trial model contributes to anti-serendipity" (p. 1064). Most modern-era psychopharmacology inventions originated in "serendipitous" observations of creative, bold minds: lithium, tricyclic antidepressants, and even electroconvulsive therapy. Creativity cannot be regulated; it dies by regulation - at least regulation taken to excess. Certainly, we need advances in patient safety and quality assurance. But the extent of external demands on our time, energy, and focus takes us further away from exploratory processes.

Third, the way we have been teaching and evaluating our trainees is not geared toward creative thinking. Our current models of evaluation presuppose that test taking proves competency and offers little more than demonstrating memorization and thinking by association. For example, most residents could easily recall "Copper=Wilson's disease" (an illness that only a few have ever seen in their lifetimes). Our examinations tend to reflect a kind of digital mentality. Multiple-choice tests have replaced essays. But clearly, when we read a narrative about a clinical situation, we learn much more about how a student thinks. Although our students and residents do require a factual knowledge base and grounding in scientific theory, these must be integrated with an expectation that thoughtful, innovative questions and alternative approaches are welcome and, indeed, expected. These two approaches are not mutually exclusive.

Decision-making in life and medicine is not predicated on digital, black-and-white thinking. It is sadly apparent that in medicine, the constraints of the drop-down menu mentality, the digital world of hashtags, and stock formulae stifle openminded thought. In clinical work, how often do we prematurely close our creative hypotheses? Sir Ken Robinson [7] argues in his TED talk that creativity is "as important in education as literacy," yet our pedagogy and system of care may well be educating people out of their creative capacities. Kelly [8], rephrasing Robinson, says, "Our education system turns out good workers rather than creative thinkers and ... the mounting challenges of our world require human beings to reach their full creative potential" (p. 1476).

\section{What Could Be Done?}

As Roberts [1] notes, we need to reflect on and effect a cultural change that affords, indeed, encourages and applauds, opportunities for creative thinking.

So, what does creativity require and what can be done?

First, creativity is deeply personal. It derives from one's knowledge, experience, and open-mindedness to observation and science, filtered through personality and imagination with the freedom to express it. Sometimes, this is a solo operation, but most artists and scientists tell us that the creative process requires connection with something external-a mentor, colleague, guide - someone who has the influence to spark the creative flame.

Second, it involves community. Creativity, as we noted, is fueled by collaborating, sharing ideas, observing, experiencing, and learning about the work of others. No doubt from artist colonies, to communities such as Walden, to participation in scientific meetings and healthy medical institutional and organizational cultures, we need communal interactions for inspiration and support. We drink "water pie" together [1]. We can immerse ourselves in music, dance, theoretical conversation, and bantering with others. Creativity demands connection with others.

Third, creativity demands breaking the bonds that bind us. Look at very young children's art in comparison to the overstylized house, tree, and person drawings of the schoolage child. Something is lost, and it is not simply due to cognitive development. It is inclusion of an artificial standard template that ensures uniformity. Kids, just as well as medical 
students and residents, have external standards that expect them to "get it right." As Robinson points out, however, children are not frightened of being wrong [7]. He continues:

What we do know is, if you're not prepared to be wrong, you'll never come up with anything original. If you're not prepared to be wrong. And by the time they get to be adults, most kids have lost that capacity. They have become frightened of being wrong. And we run our companies like this... we stigmatize mistakes. [7]

Fourth, creativity requires a different approach to teaching. We need to foster the autonomy of young trainees to seek their own solutions and place them in environments that foster creativity and networking [5]. We need to realize that technology does not necessarily foster creativity. For instance, a computer cannot replicate the art of a sound clinical interview. Real communication requires attachment, connection, empathic awareness, and improvisation. An elegant interview is a creative endeavor. Manual-based interviews obstruct the creative, interactive process and generate far less data for our clinical understanding and intervention. And while some hope that simulation may prove more valuable than multiple-choice examinations, it cannot replicate the real-time interaction with patients and thoughtful supervision.

As educators, we need to modify our educational precepts to promote the fact that creativity is part and parcel of every patient encounter and requires daily integration with our knowledge, skills, and attitudes. And we should not be training physicians to meet artificial standards of precision and reproducibility, emulated through our standardized diagnostic instruments. Whereas this kind of "precision" may be valued in clinical research, it can never replicate the data a good clinician may garner from a deeply personal interaction with a patient, ideally over the long run. After all, even in research, the most rigorous investigators have seriously questioned the notion of inter-rater reliability. Human beings and their lives are complicated and require creative curiosity so that each individual is treated uniquely with a clinician's emotional intelligence incorporated into each patient-doctor relationship.

The emphasis on evidence-based practice has been unduly influenced by this ethos. Evidence, narrowly defined, excludes the critical value of intuition, emotional intelligence, and the complexities of human interaction. It also thwarts the emergence of reflective practice. We need to expand our concept of evidence to open our hearts and minds to novel thinking, feeling, and interpersonal communication. Creative expression of scientific observation and principles through poetry, narratives, and other media can enrich medical science and education [9]. Medical humanities foster awareness, reflection, and unbridled perception.

Fifth, imaginative thinking is a part of creativity and needs to be fostered. Kelly [8] mentions, "Einstein, [pointing] to the importance of the imagination in influencing his work, [states] that 'imagination is more important than knowledge,' and 'when I examine myself and my methods of thought, I come to the conclusion that the gift of fantasy has meant more to me than any talent for abstract, positive thinking"' (p. 1476).

David Foster Wallace, in his one and only commencement address (for Kenyon College in 2005), captured much of this [10]:

There are these two young fish swimming along and they happen to meet an older fish swimming the other way, who nods at them and says, "Morning, boys. How's the water?" And the two young fish swim on for a bit, and then eventually one of them looks over at the other and goes, "What the hell is water?" (pp. 3, 4).

His work This is Water [10] expresses what we wish to point out in this commentary. He continues, "The ... point of the fish story is that the most obvious, ubiquitous, important, realities are often the ones that are hardest to see and talk about" (p. 8).

Wallace challenges the traditional notion that college teaches one how to think. And if it does, it stifles creativity and awareness of oneself and the world. We in medicine fall prey to the same theory of education. Wallace posits that what is critical is having the ability and freedom to choose what to think.

We need to purify our water if we wish to make creative advances in our science, art, and lives.

Disclosures On behalf of all authors, the corresponding author states that there is no conflict of interest.

\section{References}

1. Roberts LW. Water pie: creativity and leadership in academic psychiatry. Acad Psychiatry. 2015. doi:10.1007/s40596-015-0355-4.

2. Andreasen NC, Ramchandran K. Creativity in art and science: are there two cultures? Dialogues Clin Neurosci. 2012;14:49-54.

3. Kuhn TS. The structure of scientific revolutions. Chicago: University of Chicago Press; 1962.

4. Quine WV. Word and object. Cambridge: Technology Press of the Massachusetts Institute of Technology; 1960.

5. Fang FC, Casadevall A. Competitive science: is competition ruining science? Infect Immun. 2015;83:1229-33.

6. Klein DF. The loss of serendipity in psychopharmacology. JAMA. 2008;299:1063-5.

7. Robinson K. How schools kill creativity. Available at http://www. ted.com/talks/ken_robinson_says_schools_kill_creativity.html. Accessed April 9, 2015.

8. Kelly N. What are you doing creatively these days? Acad Med. 2012;87:1476.

9. Brown SA. Creative expression of science through poetry and other media can enrich medical and science education. Front Neurol. 2015;6:1-5.

10. Wallace DF. This is water: some thoughts on delivered on a significant occasion, about living a compassionate life. New York: Little Brown; 2009. 